\title{
Colitis and chronic bleeding in patients treated with dasatinib
}

\author{
Leonardo Campiotti ${ }^{1, *}$, Matteo B. Suter ${ }^{2}$, Elena Bolzacchini ${ }^{2}$, Silvia Uccella ${ }^{3}$, Anna M. Grandi ${ }^{1}$ and Luigina Guasti $^{1}$ \\ ${ }^{1}$ Department of Clinical and Experimental Medicine, University of Insubria, Varese, Italy \\ ${ }^{2}$ Department of Medical Oncology, Ospedale di Circolo e Fondazione Macchi, ASST Sette Laghi, Varese, Italy \\ ${ }^{3}$ Department of Medicine and Surgery, University of Insubria, 21100 Varese, Italy
}

\begin{abstract}
Dasatinib is a key therapeutic option in patients with chronic myeloid leukemia. Previous case reports associated it with acute colitis. This is another report that demonstrates a link between dasatinib and chronic colitis akin to inflammatory bowel disease, in patients undergoing therapy with dasatinib for a prolonged time.
\end{abstract}

Keywords: CML; dasatinib; colitis; toxicity

\section{Introduction}

Dasatinib is a tyrosine kinase inhibitor (TKI) approved for first and second line therapy in chronic myeloid leukemia $(\mathrm{CML})$ and Philadelphia-positive acute lymphocytic leukemia.

The most common side effect of dasatinib is hematologic toxicity, while the most common non-hematologic side effects are pleural and pericardial effusions [1]. Few reports are available regarding gastrointestinal toxicity and a very few cases of dasatinib-related acute colitis have been reported [2-4].

\section{Case report and discussion}

Since 2009, we treated 14 patients affected by CML in chronic phase with dasatinib $100 \mathrm{mg}$ per day. Five patients, all of them with a major molecular response, (BCR-ABL transcript level $<0.01 \%$ IS) developed abdominal pain and mild diarrhea (grade 1 or 2 according to CTCAE v4.0) at 13, 16, 18, 20 and 22 months from the start of therapy, associated with hypochromic microcytic anemia (grade 1 or 2 according to CTCAE v4.0) and low serum ferritin level in two cases. All symptomatic patients had fecal occult blood. A colonoscopy was performed, showing in all cases an erythematous colonic mucosa, associated in three cases with diffuse small aphthous ulceration.

Colonic mapping was performed in all of the patients; colonic mucosa appeared erythematous but substantial macroscopic differences were not found between the colonic tracts.

Microscopic examination of bioptic samples demonstrated mild glandular distortion, focal mucus depletion and a dense inflammatory infiltrate with neutrophil, lymphocytes, plasma cells and macrophages. No cryptic abscesses were observed (Figure 1). Clostridium difficile, cytomegalovirus $(\mathrm{CMV})$, bacterial and parasitic infections were ruled out with specific tests.

Dasatinib treatment was suspended in all cases. The three patients with macroscopic mucosal lesions also received prednisone $25 \mathrm{mg}$ per day for one month and mesalazin $3 \mathrm{~g}$ per day for two months. A new colonoscopy was performed three months after the first one, showing the regression of macroscopic lesions: histology demonstrated a normal colonic mucosa in all cases. All patients restarted therapy with a reduced dose of dasatinib (i.e., $80 \mathrm{mg}$ per day). In one case, clinical signs of colitis reappeared after one month and dasatinib was permanently changed with another TKI.

\section{Conclusion}

Our experience seems to indicate that gastrointestinal toxicity in patients affected by chronic myeloid leukemia in therapy with dasatinib is not uncommon (5/14). In all of our

\footnotetext{
*Corresponding author: Leonardo Campiotti, UO Medicina 1, Ospedale di Circolo e Fondazione Macchi, Viale Borri 57, 21100, Varese, Italy. Tel.: +39-0332-278831; Fax: +39-0332-278229; Email: leonardo.campiotti@ uninsubria.it
}

Received 17 February 2017 Revised 23 April 2017 Accepted 11 May 2017 Published 23 May 2017

Citation: Campiotti L, Suter MB, Bolzacchini E, Uccella S, Grandi AM, Guasti L. Colitis and chronic bleeding in patients treated with dasatinib. J Cancer Res Ther. 2017; 5(5):32-33. DOI: 10.14312/2052-4994.2017-6

Copyright: (C) 2017 Campiotti L, et al. Published by NobleResearch Publishers. This is an open-access article distributed under the terms of the Creative Commons Attribution License, which permits unrestricted use, distribution and reproduction in any medium, provided the original author and source are credited. 


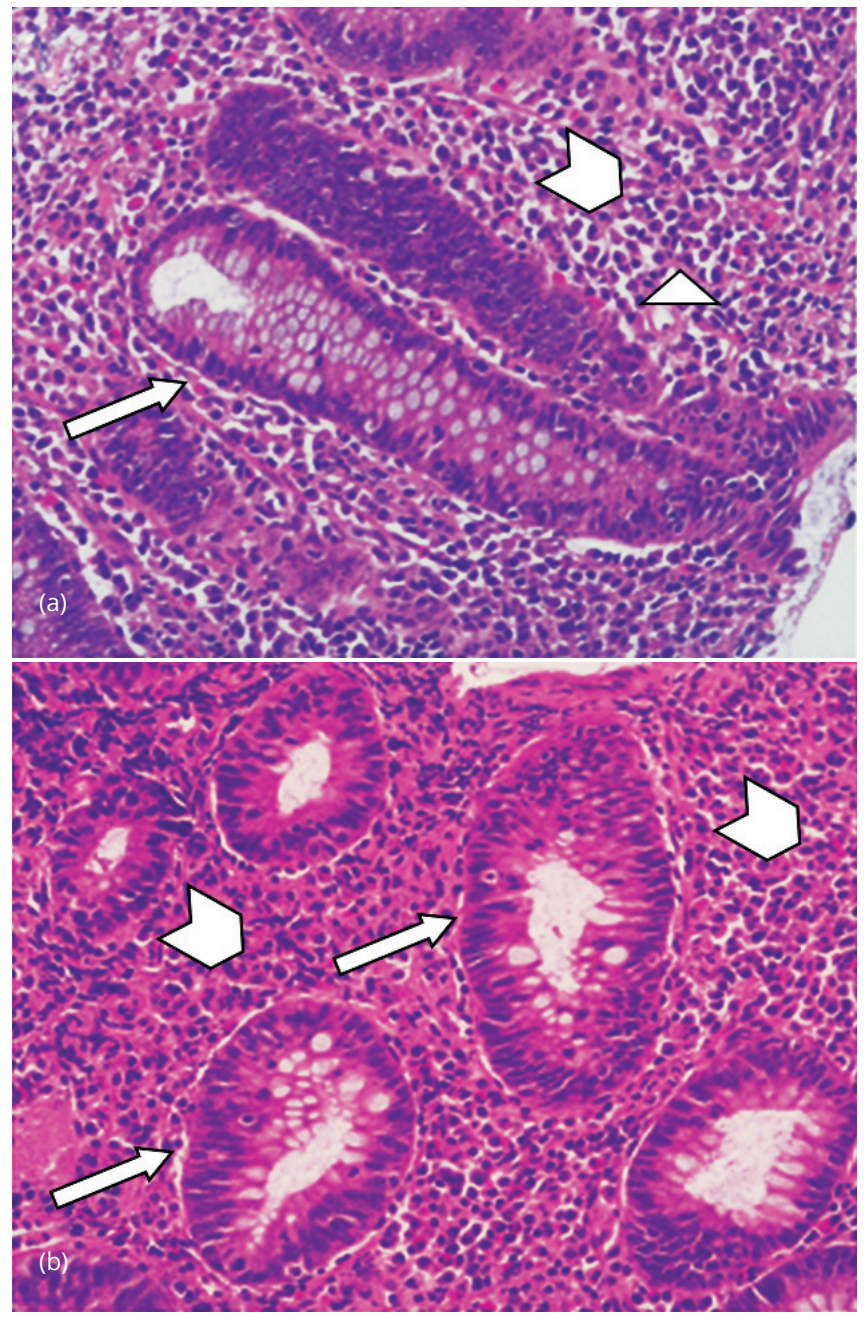

Figure 1a,b Bioptic samples of colonic mucosa in two different patients with CML treated with dasatinib. In both cases, there is a mild distortion and mucus depletion in colonic glands (arrows) and a dense polymorphic inflammatory infiltrate in the lamina propria with numerous eosinophils (arrowheads). Cryptic microabscesses are absent (Hematoxylin and eosin, x200).

patients who developed gastrointestinal toxicity we found occult colonic bleeding. We suggest to perform a fecal occult blood test periodically during chronic treatment with dasatinib. In selected cases with symptoms such as abdominal pain and diarrhea, or presence of fecal occult blood, a colonoscopy should be considered.

\section{Conflict of interest}

The authors declare that they have no conflict of interests.

\section{References}

[1] Masiello D, Gorospe G 3rd, Yang AS. The occurrence and management of fluid retention associated with TKI therapy in CML, with a focus on dasatinib. J Hematol Oncol. 2009; 2:46.

[2] Patodi N, Sagar N, Rudzki Z, Langman G, Sharma N. Haemorrhagic colitis caused by dasatinib. Case Rep Hematol. 2012; 2012:417106.

[3] Nishiwaki S, Maeda M, Yamada M, Okuno S, Harada Y, et al. Clinical efficacy of fecal occult blood test and colonoscopy for dasatinib induced hemorrhagic colitis in CML patients. Blood. 2017; 129(1):126128.

[4] Shanshal M, Shakespeare A, Thirumala S, Fenton B, Quick DP. Dasatinib induced T-Cell mediated colitis: A case report and review of the literature. Acta Haematol. 2016; 136(4):219-228.
[5] Sunami $Y$, Sato E, Ichikawa K, Yasuda H, Komatsu N. Hemorrhagic colitis caused by dasatinib following cytomegalovirus enterocolitis in a patient with chronic myelogenous leukemia in the second chronic phase. Rinsho Ketsueki. 2011; 52(5):282-286.

[6] Rodriguez GH, Ahmed SI, Al-akhrass F, Rallapalli V, Safdar A. Characteristics of, and risk factors for, infections in patients with cancer treated with dasatinib and a brief review of other complications. Leuk Lymphoma. 2012; 53(8):1530-1535.

[7] Kmira Z, Nesrine BS, Houneida Z, Wafa BF, Aida S, et al. Severe hemorrhagic colitis in a patient with chronic myeloid leukemia in the blastic phase after dasatinib use. World J Gastrointest Pathophysiol. 2013; 4(3):59-62.

[8] Hoshino T, Tahara K, Miyawaki K, Hatsumi N, Takada S, et al. Clinical profiles of 7 patients with chronic myelogenous leukemia or Philadelphia chromosome-positive acute lymphoblastic leukemia treated with dasatinib. Rinsho Ketsueki. 2010; 51(3):181-188.

[9] Quintás-Cardama A, Kantarjian H, Ravandi F, O'Brien S, Thomas D, et al. Bleeding diathesis in patients with chronic myelogenous leukemia receiving dasatinib therapy. Cancer. 2009; 115(11):2482-2490.

[10] Uchiyama T, Sato N, Narita M, Yamahira A, Iwabuchi M, et al. Direct effect of dasatinib on proliferation and cytotoxicity of natural killer cells in in vitro study. Hematol Oncol. 2013; 31(3):156-163.

[11] Kreutzman A, Jaatinen T, Greco D, Vakkila E, Richter J, et al. Killer-cell immunoglobulin-like receptor gene profile predicts good molecular response to dasatinib therapy in chronic myeloid leukemia. Exp Hematol. 2012; 40(11):906-913. 